\title{
POSTSYNTHESIS OF TITANIUM INCORPORATED WITH AMINO-FUNCTIONALIZATION UIO-66 FOR ENHANCING $\mathrm{CO}_{2}$ UPTAKE
}

\author{
Jinlong Ge,*, Zhong Wu ${ }^{\mathrm{a}}$, Qiuqin Wanga and Shanshan Yang ${ }^{\mathrm{a}}$ \\ ${ }^{a}$ School of Material and Chemistry Engineering, Bengbu University, Bengbu 233030, P. R.China
}

Recebido em 23/03/2018; aceito em 28/06/2018; publicado na web em 28/11/2018

\begin{abstract}
Metal-organic frameworks (MOFs) are promising nanomaterials with unprecedented capacity to store small molecules. Titanium cooperated with $\mathrm{NH}_{2}$-UiO-66 were prepared via post synthesis modifications approach and their structures and properties were characterized by X-raydiffraction,Fourier transform infrared spectroscopy, thermogravimetric analysis, nitrogen adsorption isotherms, and scanning electron microscopy. The resultant titanium cooperated with $\mathrm{NH}_{2}-\mathrm{UiO}-66$ showed excellent performance for $\mathrm{CO}_{2}$ adsorption via the formation of oxo-bridged hetero- $\mathrm{Zr}$-Ti clusters. This result clearly demonstrates that the smaller Ti ions exchanged with the $\mathrm{Zr}$ ions of $\mathrm{NH}_{2}-\mathrm{UiO}-66$ may decrease the pore sizes within the framework to be closer to the ideal pore sizes for $\mathrm{CO}_{2}$ adsorption.
\end{abstract}

Keywords: metal-organic frameworks; $\mathrm{NH}_{2}-\mathrm{UiO}-66 ; \mathrm{CO}_{2}$ uptake; Titanium

\section{INTRODUCTION}

As a new class of hybrid porous crystalline materials, metalorganic frameworks (MOFs) typically constructed from metal oxoclusters interconnected by polydentate organic ligands, have a definite composition and structure. ${ }^{1}$ Permanent microporosity, adjustable porosities, tunable pore suface,typically very high internal surface areas and low densities make MOFs material promising candidates in the area of gas storage, ${ }^{2}$ separation, heterogeneous catalysis, chemical sensing and drug delivery. ${ }^{3}$ Additionally,porous MOF compounds provide distinct advantages over other classes of adsorbents and heterogeneous catalysts. ${ }^{4}$

Nowadays, the rising level of carbon dioxide in the atmosphere has become one of the biggest problems worldwide. ${ }^{5}$ Therefore, reducing carbon dioxide emission from the burning processes by capture and storage has been proposed as one of the control strategies and thus has been studied by many researchers throughout the world using different technologies. ${ }^{6}$ With current technology, the most effective method of $\mathrm{CO}_{2}$ capture from flue gases is chemical absorption in an aqueous solution of an amine based organic, such as mono- or diethanol-amine. ${ }^{7}$ Furthermore, the degradation of the amine absorbent leads to corrosive mixtures.Among these methods, recent advances have shifted towards adsorption technology using novel materials such as MOFs to controlling the $\mathrm{CO}_{2}$ emission from flue gases. ${ }^{8}$ In addition to a high surface area and pore volume, MOFs chemical nature can be fine-tuned by selecting the appropriate building blocks and/or by post-synthetic modification, thus leading to tailored porous materials with great promise for the $\mathrm{CO}_{2}$ adsorption. ${ }^{9}$

Recently, Zr-based MOFs (UiO-66), which with free diameter of octahedral cage is $11 \AA$ and tetrahedral cage is $8 \AA$, and the cages are connected by triangular windows with a diameter of $6 \AA$, have been found to have good thermal stability and adsorption capacity toward $\mathrm{CO}_{2}$. Different ligand linkers have been tested for adsorption of $\mathrm{CO}_{2}$ such as $\mathrm{NH}_{2}-\mathrm{BDC}$ and $\mathrm{Br}-\mathrm{BDC} .{ }^{10}$ Possess high surface areas, large cavity volumes, robust and stable at high temperatures and in atmospheric moisture, $\mathrm{NH}_{2}$-UiO-66 is an ideal candidate for $\mathrm{CO}_{2}$ capture. ${ }^{11}$

The partial substitution of metal cations in MOFs can lead to the formation of oxo-bridged heterometallic assemblies within the same

*e-mail: jinlongge2005@126.com
MOFs. Such bimetallic assemblies with more flexibility and tunability due to the availability of different MOF structures, are expected to show enhanced photocatalytic performance. ${ }^{12}$ The incorporation with metal ions in MOFs is considered one of the effective ways to modify the pore sizes of MOFs. Post-synthesis modifications of preconstructed MOFs by replacement of the organic cation with smaller inorganic cation have been performed to tune the pore size and provide desired surface chemistries in MOFs. This postsynthetic exchange of ligands occurred with full retention of crystallinity and porosity as gas sorption measurements. ${ }^{13}$

$\mathrm{NH}_{2}-\mathrm{UiO}-66$ is suitable for postsynthetic modification with a variety of anhydrides to generate new functionalized frameworks. The amine tagged $\mathrm{NH}_{2}$-UiO-66 has been explored in post-synthesis modifications reactions, Cohen and Lillerud ${ }^{14}$ independently reported the acylation of $\mathrm{NH}_{2}-\mathrm{UiO}-66$ via the use of anhydride reagents. The aziridination of the amino group has been performed in $\mathrm{NH}_{2}$-UiO-66 with acetaldehyde. Wang et al. ${ }^{15}$ reported via a facial modified post-grafting method prepared UiO-66 fabricated with titanium. Ti-substituted $\mathrm{NH}_{2}-\mathrm{UiO}-66(\mathrm{Zr} / \mathrm{Ti})$ prepared by Sun et.al. using a post-synthetic exchange method showed enhanced photocatalytic performance for both $\mathrm{CO}_{2}$ reduction.

We herein report the synthesis of titanium cooperated with $\mathrm{NH}_{2}-$ UiO-66 via a facial modfied post-grafing method. The $\mathrm{CO}_{2}$ adsorption performance of the as-synthesized $\mathrm{NH}_{2}-\mathrm{UiO}-66(\mathrm{Ti})$ nanocomposites was evaluated.

\section{EXPERIMENTAL}

\section{Materials}

Zirconium chloride $\left(\mathrm{ZrCl}_{4}\right)$, 2-aminoterephthalic acid (SigmaAldrich.>99\%), N,N-dimethylformamide (DMF) and ethanol were purchased from Shanghai Chemical Reaent Inc. of the Chinese Medicine Group. Tetrabutyl titanate $\left(\mathrm{Ti}(\mathrm{OBu})_{4}\right)$ were ordered from Aladdin,All chemicals were used without further purification.

\section{Synthesis of amino-functionalized $\mathrm{NH}_{2}-\mathrm{UiO}-66$}

A standard up scaled synthesis of $\mathrm{NH}_{2}-\mathrm{UiO}-66$ was performed by dissolving $\mathrm{ZrCl}_{4}(1.50 \mathrm{~g}, 6.4 \mathrm{mmol})$ and 2-aminoterephthalic acid (1.56 
$\mathrm{g}, 6.4 \mathrm{mmol})$ in DMF $(180 \mathrm{~mL})$ at room temperature in a volumetric flask. ${ }^{16}$ The resulting mixture was placed in a preheated oven at 80 for $12 \mathrm{~h}$ and then held at $100{ }^{\circ} \mathrm{C}$ for $24 \mathrm{~h}$. After the solution was cooled to room temperature in air, the resulting solid was filtered and repeatedly washed with absolute ethanol for 3 days while heated at $60{ }^{\circ} \mathrm{C}$ in a water bath. The resulting yellow powder was filtered and dried under vacuum at ambient temperature.

\section{Synthesis of $\mathrm{TiCl}_{4}(\mathrm{THF})_{2}$}

$\mathrm{TiCl}_{4}(\mathrm{THF})_{2}$ was synthesized according to the patent of Francesco et al. ${ }^{17} 5.0 \mathrm{~g} \mathrm{TiCl}_{4}$ was dissolved in $50 \mathrm{~mL}$ of dichloroethane in a $250 \mathrm{~mL}$ RBF under inert conditions. $7.62 \mathrm{~g}$ dried tetrahydrofuran (THF) was added at $0{ }^{\circ} \mathrm{C}$ to form a yellow solution. $100 \mathrm{~mL}$ of sodium dried n-hexane was used to precipitate a yellow powder, which was filtered and washed with n-hexane. It was dried for 2-3 hours over a Schlenk line, and used immediately for post-synthetic exchange.

\section{Post-synthetic exchange of $\mathrm{UiO}-66$ with $\mathrm{TiCl}_{4}(\mathrm{THF})_{2}$}

The post-synthetic exchange of UiO-66 with $\mathrm{TiCl}_{4}(\mathrm{THF})_{2}$ was carried out according to the work of Cohen and co-workers. $0.17 \mathrm{~g}$ $\mathrm{TiCl}_{4}$ (THF) $)_{2}$ was dissolved in $10 \mathrm{~mL}$ of DMF. $0.14 \mathrm{~g}$ of $\mathrm{NH}_{2}-\mathrm{UiO}-66$ was added. (denoted as $\mathrm{NH}_{2}$-UiO-66 (Ti)-0.2, 0.4, 0.6, 0.8, 1.0, respectively). The mixture was incubated for 5 and 15 days. The solids were separated from the solvent via centrifugation, and washed with fresh DMF. The washed solids were immersed in a methanol bath for 3 days. The methanol was replaced every 24 hours. The solids were dried at $40{ }^{\circ} \mathrm{C}$ in a vacuum for 24 hours.

\section{Characterizations}

Powder X-ray diffraction (PXRD) patterns were collected by using an X-ray diffract meter with $\mathrm{Cu}$ target $(36 \mathrm{kV}, 25 \mathrm{~mA})$ from 5 to $70^{\circ}$. Ultraviolet-visible (UV-vis) absorbance spectra were collected on a Shimadzu UV 3600 plus spectrophotometer over a range of 200-800 $\mathrm{nm}$. Infrared (IR) spectra (KBr pellets) were obtained in the $400-4000 \mathrm{~cm}^{-1}$ rang with a resolution of $4 \mathrm{~cm}^{-1}$ using a Nicolet Nexus 870 FTIR spectrometer. Nitrogen sorptiondesorption isotherms were obtained at $77 \mathrm{~K}$ on a Micromeritics ASAP 3020 analyzer. The samples were heated at $150{ }^{\circ} \mathrm{C}$ for $12 \mathrm{~h}$ prior to each test. Morphology and microstructure were observed by a field emissions scanning electron microscope (FE-SEM: Hitachi S-4800) and high resolution transmission electron microscopy (TEM: JEOL JEM 2100). Transmission electron microscope was operated at $200 \mathrm{kV}$. Thermogravimetric Analysis was performed on an in the tempteature range of $30-900{ }^{\circ} \mathrm{C}$ under nitrogen at a heating rate of $20^{\circ} \mathrm{C} \mathrm{min}^{-1}$,using a Pyris1 TGA-1.

\section{RESULTS AND DISCUSSION}

\section{Characterization of $\mathrm{Ti} / \mathrm{NH}_{2}-\mathrm{UiO}-66$}

\section{XRD, FI-IR measurements}

XRD patterns of the $\mathrm{NH}_{2}-\mathrm{UiO}-66$ and $\mathrm{UiO}-66$ (Ti) nanocomposite was presents as Figure 1. All the $\mathrm{NH}_{2}-\mathrm{UiO}-66(\mathrm{Ti})$ exhibited a similar XRD pattern as reported in the literature. The samples present sharper and narrower diffraction peaks at $2 \theta=7.3^{\circ}, 8.5^{\circ}, 17.1^{\circ}, 25.8^{\circ}$ and $30.8^{\circ}$, indicating the higher crystallinity. ${ }^{18}$ Peaks corresponding to newly emerged phases cannot be observed even at higher $\mathrm{Ti}$ concentration. It suggested that the introduction of titanium does not result in any destruction or disorder in comparison to the $\mathrm{NH}_{2}$-UiO-66 sample. ${ }^{19}$ Additionally, with the increasing of the Ti to $\mathrm{Zr}$ molar ratio, the partial substitution of larger $\mathrm{Zr}$ in $\mathrm{Zr}-\mathrm{O}$ oxoclusters replaced by smaller $\mathrm{Ti}$, this suggests that $\mathrm{Zr}$ in the original $\mathrm{NH}_{2}-\mathrm{UiO}-66$ has been substituted by $\mathrm{Ti} . \mathrm{NH}_{2}-\mathrm{UiO}-66$ framework was reformed and substituted by the titanium species with Ti-O clusters, $\mathrm{NH}_{2}-\mathrm{UiO}-66$ shows not well-ordered porous structure. ${ }^{20}$

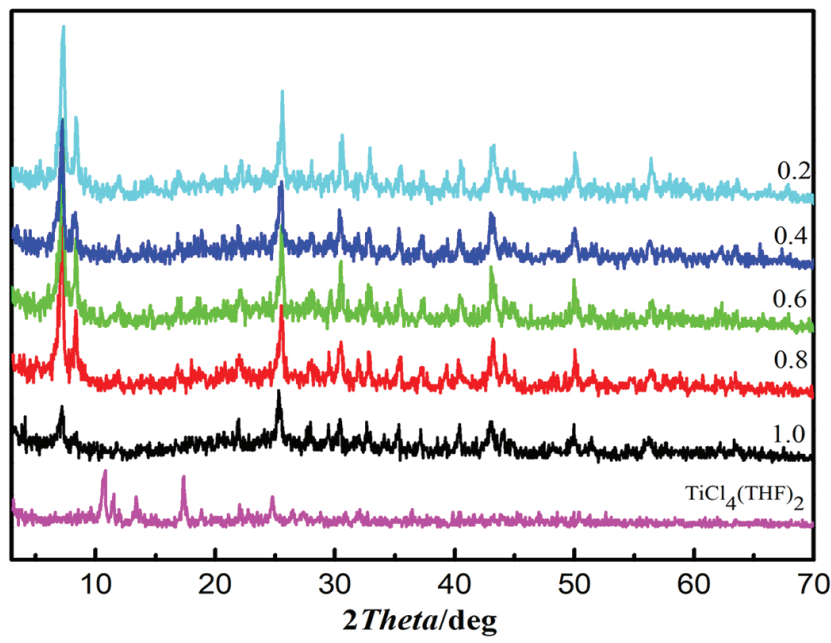

Figure 1.XRD spectra of Ti incorporated with $\mathrm{NH}_{2}-\mathrm{UiO}-66$

The FTIR spectra of these $\mathrm{Ti} / \mathrm{NH}_{2}$-UiO-66 samples exhibit similar characteristic peaks, as shown in Figure 2.The two intense bands around 1569.15 and $1386.53 \mathrm{~cm}^{-1}$ are associated with the C-O asymmetric and symmetric stretch vibrations in the carboxylate group in $\mathrm{NH}_{2} \mathrm{BDC}$, respectively. ${ }^{21}$ The small band around $1497.35 \mathrm{~cm}^{-1}$ represents the vibration of $\mathrm{C}-\mathrm{C}$ in the benzene ring. The 1361.25 $\mathrm{cm}^{-1}$ absorption band is attributed to the $\mathrm{C}-\mathrm{N}$ stretching. Additional peaks between $664.89-964.80 \mathrm{~cm}^{-1}$ are associated with bending and twisting of the $\mathrm{Zr}$ node. ${ }^{22}$ Shoulder peaks are associated with the loss of symmetry at the $\mathrm{Zr}$ node, but are difficult to distinguish. The $\mathrm{Zr}-\mathrm{Cl}$ stretch is difficult to assign to one specific mode but occurs in the same frequency range as the $\mathrm{Zr}-\mathrm{O}$ stretches between 483.20 and $582.96 \mathrm{~cm}^{-1}$.

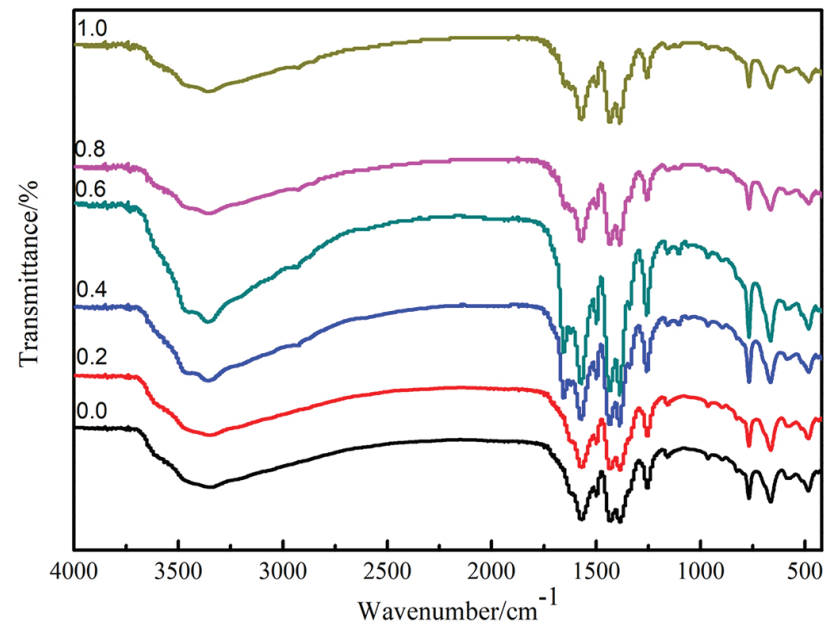

Figure 2.FTIR spectra of Ti incorporated with $\mathrm{NH}_{2}-\mathrm{UiO}-66$

\section{TG,BET measurements}

Thermogravimetric analyses were carried out in an air atmosphere for investigation of the thermal stability of the compound. As displayed in Figure 3, the $\mathrm{Ti}$ incorporated with $\mathrm{NH}_{2}-\mathrm{UiO}-66$ was accordance with previous studies. ${ }^{23}$ The framework decomposition is occurs 
over a temperature range of $540{ }^{\circ} \mathrm{C}$. All the samples are occur loss of physisorbed water molecules and solvent molecules hosted in the pores over a temperature range of $35-100{ }^{\circ} \mathrm{C}$. The progressive structured weight loss up to $200-350{ }^{\circ} \mathrm{C}$ are the removal of monocarboxylate ligands and dehydroxylation of the $\mathrm{Zr} 6$ cornerstones. ${ }^{24}$ However, increasing the Ti concentration in the post-synthetic metal results in the plateau increasing toward ideality, indicating that more Ti have been exchange in $\mathrm{NH}_{2}-\mathrm{UiO}-66$ structure. The TGA plateau is in fact found to systematically increase with the ratio of $\mathrm{Ti}$ to $\mathrm{Zr}^{25}$

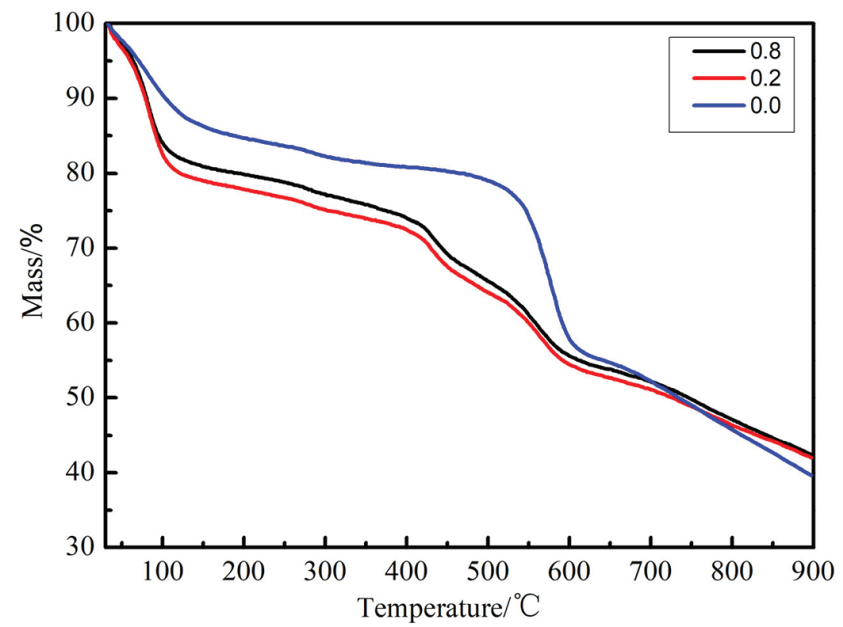

Figure 3.TG spectra of Ti incorporated with $\mathrm{NH}_{2}-\mathrm{UiO}-66$

The $\mathrm{N}_{2}$ adsorption-desorption isotherm measurement and the pore-size was performed distribution curve are shown in Figure 4. We can see that the nitrogen adsorption capacity varies significantly depending on content of Ti.

The specific BET surface area of $1227 \mathrm{~m}^{2} \mathrm{~g}^{-1}$ of $\mathrm{NH}_{2}-\mathrm{UiO}-66$ and varied to $627,563,509,484,350 \mathrm{~m}^{2} \mathrm{~g}^{-1}$ with increasing of the Ti concentration, respectively.

$\mathrm{NH}_{2}$-UiO-66(Ti) presents the lowest BET of $350 \mathrm{~m}^{2} \mathrm{~g}^{-1}$. The decreased BET indicates that the pores in the $\mathrm{NH}_{2}-\mathrm{UiO}-66$ nanocomposites are smaller than the parent $\mathrm{NH}_{2}-\mathrm{UiO}-66 .{ }^{26}$ Such phenomena are frequently observed over inorganic semiconductor solid solutions and suggest the substitution of larger $\mathrm{Zr}^{4+}$ in $\mathrm{Zr}-\mathrm{O}$ oxo-clusters by smaller $\mathrm{Ti}^{4+}$, which results in the shrinking of the crystal lattice in the porous material. ${ }^{27}$

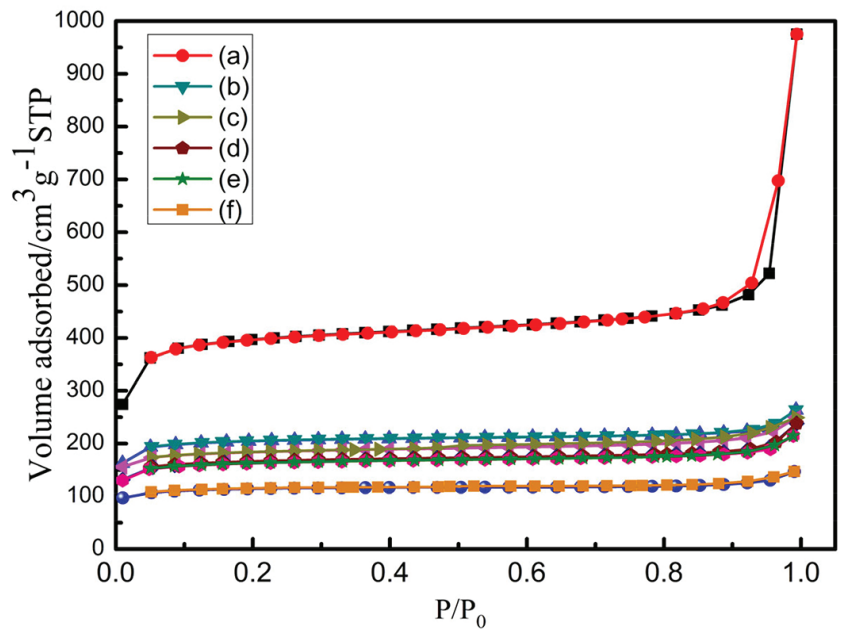

Figure 4. $\mathrm{N}_{2}$ adsorptiondesorption isotherms of Ti incorporated with $\mathrm{NH}_{2}-\mathrm{UiO}-66$
Table1. BET and pore volume of the different $\mathrm{Ti}$ incorporated with $\mathrm{NH}_{2}-\mathrm{UiO}-66$

\begin{tabular}{cccc}
\hline Ti/Zr & BET $\left(\mathrm{m}^{2} \mathrm{~g}^{-1}\right)$ & Langmuir $\left(\mathrm{m}^{2} \mathrm{~g}^{-1}\right)$ & pore $\operatorname{vol}\left(\mathrm{cm}^{3} \mathrm{~g}^{-1}\right)$ \\
\hline 0 & 1227.6 & 1889.4 & 0.52 \\
0.2 & 627.0 & 935.2 & 0.46 \\
0.4 & 563.4 & 855.4 & 0.48 \\
0.6 & 509.6 & 773.9 & 0.42 \\
0.8 & 484.2 & 755.5 & 0.38 \\
1.0 & 350.0 & 515.9 & 0.30 \\
\hline
\end{tabular}

\section{$U V$-vis measurements}

The UV-visible absorption spectra are presented in Figure 5. It shows that two main absorption peaks at around 265 and $365 \mathrm{~nm}$. The peak at $265 \mathrm{~nm}$ is ascribed to the absorption of $\mathrm{Zr}-\mathrm{O}$ clusters in the $\mathrm{NH}_{2}-\mathrm{UiO}-66$. The peak is broader than the unsubstituted $\mathrm{NH}_{2}-\mathrm{UiO}-66$, this result may be attributed to the absorption of Ti-O oxo-clusters generated by $\mathrm{Ti}$ substitution in $\mathrm{NH}_{2}-\mathrm{UiO}-66 .{ }^{28}$ The main peak at 365 $\mathrm{nm}$ is ascribed to the ligand based absorption influenced by the nearby metal centers. However, these two peaks become broader and more intense after the titanium was incorporated into $\mathrm{NH}_{2}-\mathrm{UiO}-66 .{ }^{29}$ In addition, the UV-vis absorption edges of the as-prepared $\mathrm{NH}_{2}-\mathrm{UiO}$ 66(Ti) nanocomposites are shifted to longer wavelengths compared with that of $\mathrm{NH}_{2}-\mathrm{UiO}-66$. The absorption bands in the near visible and visible regions in $\mathrm{NH}_{2}-\mathrm{UiO}-66(\mathrm{Ti})$ are mainly attributed to the ligand to metal charge transfer and can be assigned to the interaction between the ligand and substituted $\mathrm{Ti}^{30}$

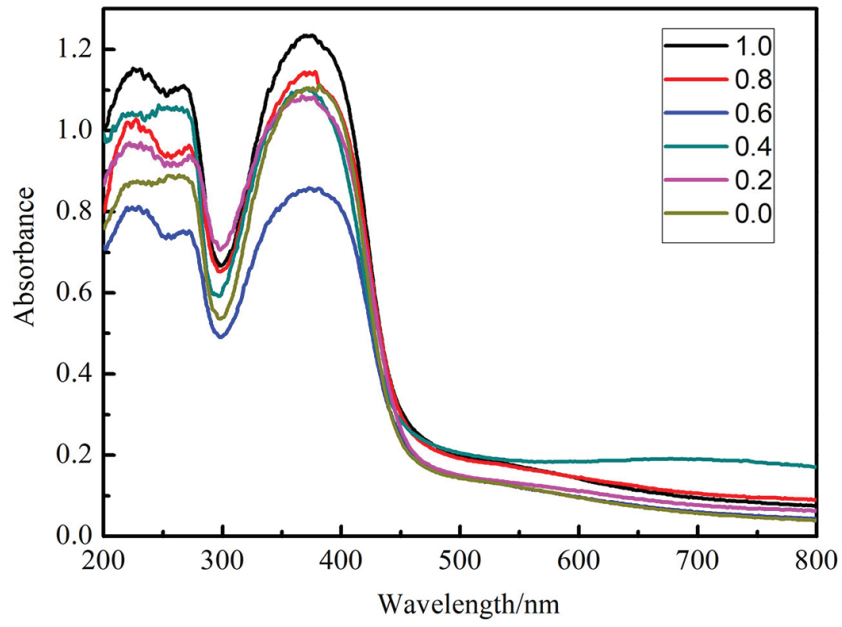

Figure 5. UV-vis spectra of Ti incorporated with $\mathrm{NH}_{2}-\mathrm{UiO}-66$

\section{XPS measurements}

The X-ray photoelectron spectroscopy (XPS) is a highly sensitive technique to explore the chemical changes in the element surroundings. The XPS spectra of the elements of interest $\mathrm{Zr3d}$, Ti2p, N1s, O1s are shown in Figure 6.The survey scan of the $\mathrm{NH}_{2}-\mathrm{UiO}-66$ and $\mathrm{NH}_{2}-\mathrm{UiO}-66(\mathrm{Ti})$ was shown in Figure 6(a), new peaks associated with Ti2p appeared in the XPS spectrum of the UiO-66(Ti) composites, and their relative peak intensities to that of $\mathrm{Zr} 3 \mathrm{p}$ increased with an increasing Ti content. These observations confirmed that the titanium moieties were successfully. The analysis Figure $6(\mathrm{c})$ of $\mathrm{NH}_{2}-\mathrm{UiO}-66(\mathrm{Ti})$ indicated a small shift in the binding energy of the $\mathrm{Zr} 3 \mathrm{~d}$ peaks (from 185.08 and $182.78 \mathrm{eV}$ to 185.28 and $182.88 \mathrm{eV}$,respectively). ${ }^{31}$ Figure $6(\mathrm{~d})$ shows two peaks of the Ti2p region at $458.7 \mathrm{eV}$ and $464.5 \mathrm{eV}$,corresponding to Ti2p3/2 and Ti2p1/2 

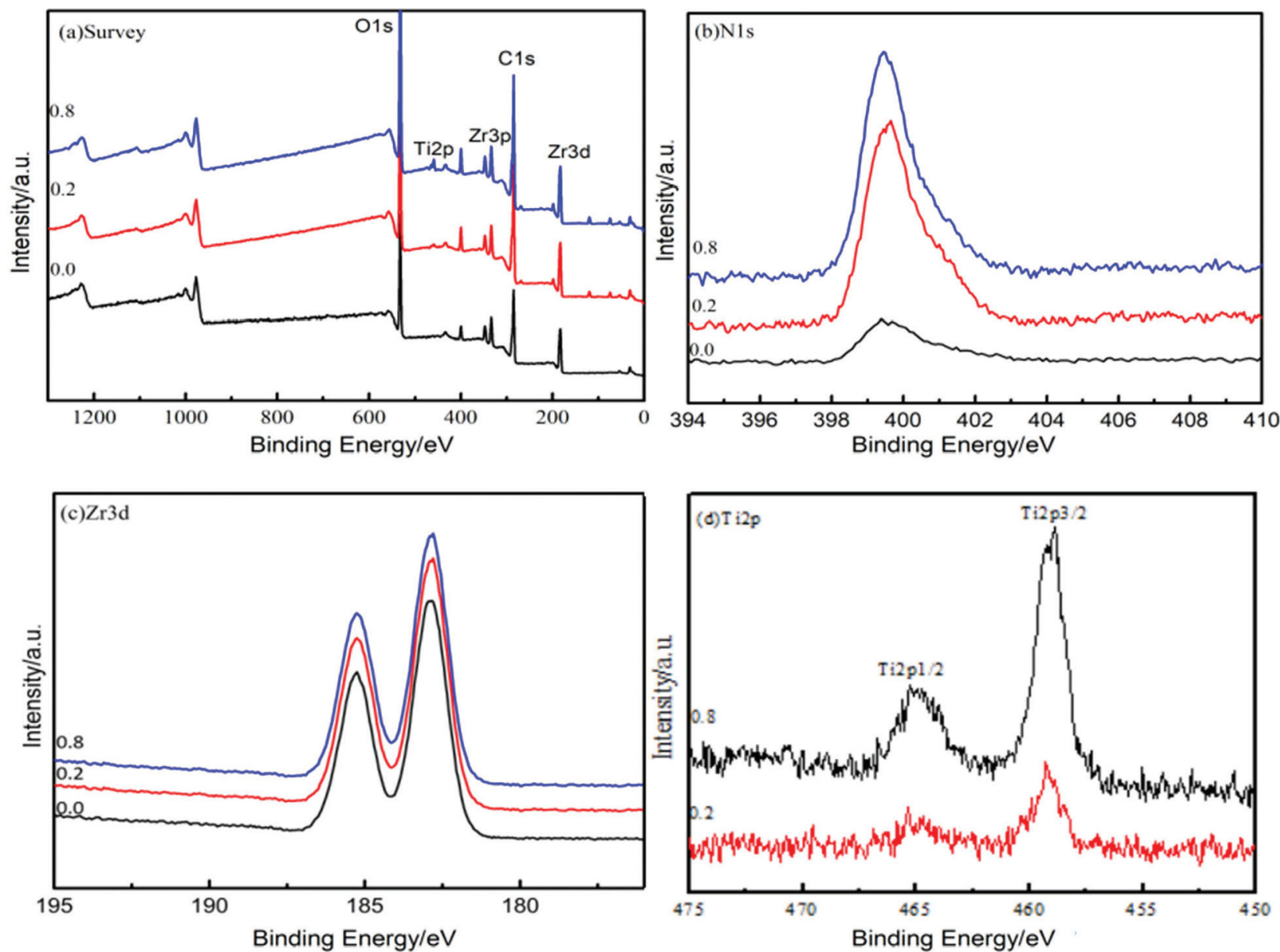

Figure 6. XPS spectra of Ti incorporated with $\mathrm{NH}_{2}-\mathrm{UiO}-66$

respectively, The increasing $\mathrm{Ti}$ contents could be explained by the enhanced electron density around the $\mathrm{O}$ atoms. All these features imply that the titanium moieties be introduced to the framework of UiO-66 as electron donor via the formation of oxo-bridged hetero-ZrTi clusters.and provided that another confirmation of the successful incorporation of the Ti moiety in $\mathrm{NH}_{2}-\mathrm{UiO}-66 .{ }^{32}$

\section{SEM and TEM measurements}

The morphology of $\mathrm{NH}_{2}-\mathrm{UiO}-66$ and the $\mathrm{NH}_{2}-\mathrm{UiO}-66(\mathrm{Ti})$ nanocomposite were investigated by SEM. According to Figure 7, it can be clearly seen from (a) that $\mathrm{NH}_{2}-\mathrm{UiO}-66$ nanocrystals were more angular, revealing the increased definition of facets and vertices that are common in larger crystals, indicating that the presence of the $\mathrm{NH}_{2}$ group on the organic linker affects the growth mechanism of the framework. ${ }^{33}$ The materials have the typical octahedral morphology, with homogeneous particle diameters about $200 \mathrm{~nm}$. Obviously, $\mathrm{NH}_{2}$-UiO-66(Ti) retained the similar morphology as $\mathrm{NH}_{2}-\mathrm{UiO}-66$. Furthermore, no obvious differences of the morphologies could be observed from the TEM images ( $g$ and $h$ ). These observations suggest that $\mathrm{Ti}$ was truly incorporated into the $\mathrm{UiO}-66$ framework to replace $\mathrm{Zr}$ as skeleton. ${ }^{34}$ No change in the octahedral morphology of the crystals could be observed. Furthermore, EDS elemental analysis was also conducted to study the elemental distribution. The EDS spectrum of $\mathrm{NH}_{2}$-UiO-66(Ti) reveals $\mathrm{N}, \mathrm{Zr}$, Ti, and $\mathrm{O}$ elements.

\section{$\mathrm{CO}_{2}$ adsorption}

The $\mathrm{CO}_{2}$ adsorption isotherms for $\mathrm{NH}_{2}-\mathrm{UiO}-66(\mathrm{Ti})$ are shown in Figure 8. All MOFs exhibited a type I isotherm, which is indeed characteristic of microporous materials. $\mathrm{NH}_{2}-\mathrm{UiO}-66(\mathrm{Ti})-0.2$ and $\mathrm{NH}_{2}$-UiO-66(Ti)-0.4 samples presented higher $\mathrm{CO}_{2}$ adsorption than $\mathrm{NH}_{2}-\mathrm{UiO}-66$ sample. And the two samples show the highest $\mathrm{CO}_{2}$ adsorption capacities. $\mathrm{NH}_{2}-\mathrm{UiO}-66(\mathrm{Ti})-0.6$ has the similar adsorption capacity as $\mathrm{NH}_{2}-\mathrm{UiO}-66$. The rate of 0.8 and 1.0 are lower than $\mathrm{NH}_{2}-\mathrm{UiO}-66$. Considering the moderate BET surface area and pore volume of Titanium incorporated with $\mathrm{NH}_{2}-\mathrm{UiO}-66$, it is likely that the high $\mathrm{CO}_{2}$ capacity is due to the average pore diameter being of an optimal size to confine $\mathrm{CO}_{2}$ molecules. ${ }^{35}$ This suggests that $\mathrm{Zr}$ in the original $\mathrm{NH}_{2}-\mathrm{UiO}-66$ has been substituted by Ti. The Ti-O ring sterically hinders access to the stronger adsorption sites at the metal cluster. ${ }^{36}$ It is noted that $\mathrm{Ti}$ has produced a higher affinity for adsorption of $\mathrm{CO}_{2}{ }^{37}$ Ti incorporated with $\mathrm{NH}_{2}$ functional groups can provide more $\mathrm{CO}_{2}$ adsorption sites and increase the affinity toward $\mathrm{CO}_{2}$. Several studies have been reported that the presence of micropores $(<0.8 \mathrm{~nm})$ in porous carbons showed superior $\mathrm{CO}_{2}$ adsorption capacity, particularly for $\mathrm{CO} 2$ capture at atmospheric pressure and room temperature. The results of $\mathrm{CO}_{2}$ adsorption indicate that not only the amount of defects but also their charge compensating groups within the materials have a marked effect on the loading of guest molecules. ${ }^{38,39}$ An important observation is the amount of uptake that occurs within the small cavities. This is remarkable considering that the small cavities of $\sim 5 \AA$ appear to have a large role in the uptake of $\mathrm{CO}_{2}$. The Titanium cooperated with $\mathrm{NH}_{2}-\mathrm{UiO}-66$ herein illustrate the importance of reactive side groups, introduced in post-synthetic modifications, converted in high yields to functionalities through post-synthetic methods. ${ }^{40}$ Moreover, our work highlights the strategies of tailoring host-guest 

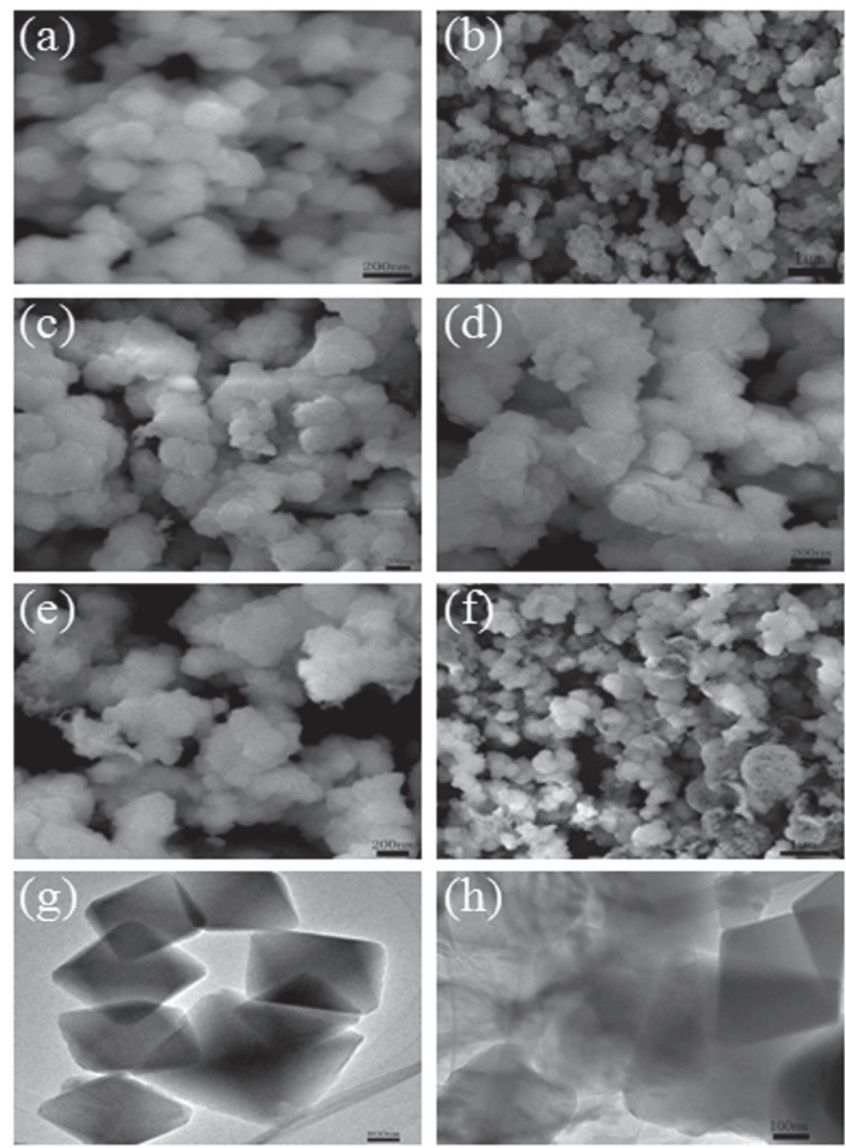

Figure 7 . SEM and TEM spectra of representative Ti incorporated with $\mathrm{NH}_{2}$-UiO-66

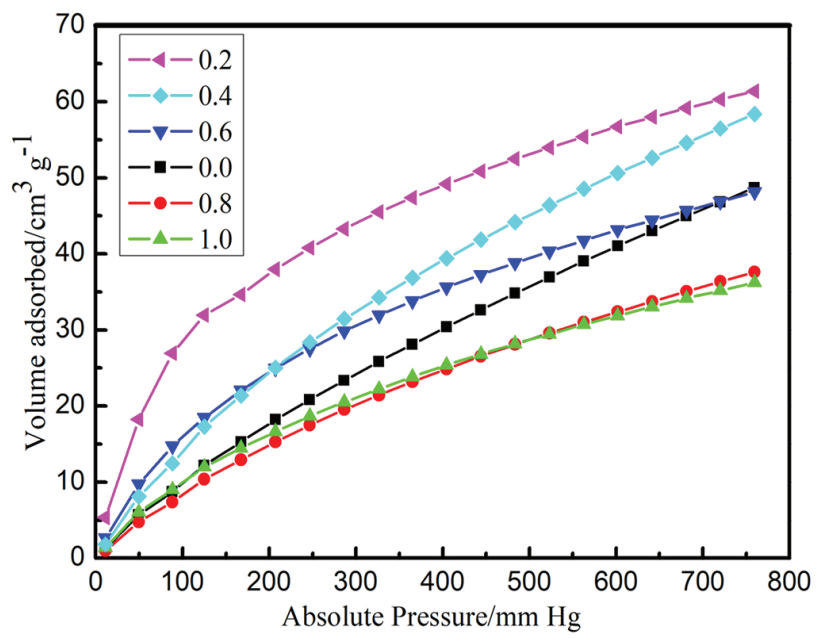

Figure 8. $\mathrm{CO}_{2}$ adsorption isotherms of Ti incorporated with $\mathrm{NH}_{2}-\mathrm{UiO}-66$

interactions through post-synthetic method, therefore, enabling applications in $\mathrm{CO}_{2}$ uptake.

Metal organic framework $\mathrm{NH}_{2}-\mathrm{UiO}-66$ fabricated with titanium was successfully prepared via a facial modified post synthesis method. $\mathrm{Zr}$ ions in $\mathrm{NH}_{2}-\mathrm{UiO}-66$ were post synthetically exchanged with $\mathrm{Ti}$ ions at different loading rate. The Ti-exchanged $\mathrm{NH}_{2}-\mathrm{UiO}-66$ enhanced $\mathrm{CO}_{2}$ adsorption could be attributed to the the substituted Ti center. This result clearly demonstrates that the Ti ions may decrease the pore sizes within the framework to be closer to the ideal pore sizes for $\mathrm{CO}_{2}$ adsorption, which are critical to the enhancing of the $\mathrm{CO}_{2}$ adsorption.

\section{ACKNOWLEDGEMENTS}

This work was supported by Funding of High Research for High Talents (BBXY2018KYQD08, BBXY2018 KYQD16) and the Project for Excellent Talents Visiting (No.gxfx2017134).

\section{REFERENCES}

1. Huang, Y. H.; Lo, W. S.; Kuo, Y. W.; Chen, W J.; Lin, C. H.; Shieh, F. K.; Chem. Commun. 2017, 43, 5818.

2. Zhou, H. F; Liu, B.; Hou, L.; Zhang, W. Y.; Wang, Y. Y.; Chem. Commun. 2018, 54, 456.

3. Zhu, S. Y.; Yan, B.; Dalton Trans. 2018, 47, 1674.

4. Hu, Z.; Zhao, D.; Dalton Trans. 2015, 44, 19018.

5. Han, Y. T; Liu, M.; Li, K. Y; Sun, Q.; Zhang, W. S.; Song, C. S.; Zhang, G. L.; Zhang, Z. C.; Guo, W; Inorg. Chem. Front. 2017, 4, 1870.

6. Yang, J.; Zhang, F. J.; Wang, X.; He, D. S.; Wu, G.; Yang, Q. H.; Hong, X.; Wu, Y.; Li, Y. D.; Angew. Chem. Int. Ed. 2016, 55, 12854.

7. Yao, B. J.; Jiang, W. L.; Dong, Y.; Liu, Z. X.; Dong, Y. B.; Chem. Eur. J. 2016, 22, 10565.

8. Zhong, Z. W; Pang, S. L.; Wu, Y. W.; Jiang, S.; Ouyang, J.; J .Chem. Technol. Biotechnol. 2017, 92, 1841.

9. Liu, J. L.; Zhu, D. D.; Guo, C. X.; Vasileff, A.; Qiao, S. Z.; Adv. Energy. Mater 2017, 1700518.

10. Taddei, M.; Dau, P. V.; Cohen, S. M.; Ranocchiari, M.; Bokhoven, J.; Costantino, F.; Sabatino, S.; Vivani, R.; Dalton. Trans. 2015, 44, 14019.

11. Zou, G. Z.; Hou, H. S.; Zhao, G. G.; Ge, P.; Yin, D. L.; Ji, X. B. J. Mater. Chem. A 2015, 6, 4839.

12. Ragon, F.; Chevreau, H.; Devic, T.; Serre, C.; Horcajada, P.; Chem. Eur. J. 2015, 21, 7135 .

13. Wu, M. X.; Yang, Y. W.; Adv. Mater 2017, 29, 1606134.

14. Zhang, X. P; Sun, W. D; Du, H. T; Kong, R. M.; Qu, F. L.; Inorg. Chem. Front. 2018, 5344.

15. Wang, A. N.; Zhou, Y. J.; Wang, Z. L.; Chen, M.; Sun , L. Y.; Liu, X. RSC. Adv. 2016, 6, 3671.

16. Peng, Y. G.; Huang, H. L.; Zhang, Y. X.; Kang, C. F.; Chen, S. M.; Song, L.; Liu, D. H.; Zhong, C. L.; Nature Commun. 2018, 9, 187.

17. Sutrisna, P. D.; Hou, J. W.; Zulkifli, M. Y.; Li, H. Y.; Zhang, Y. T.; Liang, W. B.; DAless, D. M.; Chen, V.; J. Mater. Chem. A 2018, 6, 918.

18. Han, Y. T.; Liu, M.; Li, K. Y.; Zuo, Y.; Wei, Y. X.; Xu, S. T.; Zhang, G. L.; Song, C. S.; Zhang, Z. C.; Guo, X. W.; CrystEngComm. 2015, 17, 6434.

19. Hu, Z. G.; Nalaparaju, A.; Peng, Y. W.; Jiang, J. W.; Zhao, D.; CrystEngComm. 2015, 17, 6434.

20. Sadeghzadeh, S. M.; Zhiani, R.; Emrani, S.; New. J. Chem. 2018, 42, 988.

21. Anjum, M. W.; Vermoortele, F.; Khan, A. L.; Bueken, B.; DeVos, D.; Vankelecom, I.; ACS Appl. Mater. Interfaces. 2015, 5, 25193.

22. Xian, S. K.; Wu, Y.; Wu, J. L.; Wang, X.; Xiao, J.; Ind. Eng. Chem. Res. 2015, 54, 11151.

23. Nguyen, H.; Mao, L.; Peters, A. W.; Audu, C. O.; Brown, Z. J.; Farha, O. K.; Hupp, J. T.; Nguyen, S. T.; Catal. Sci. Technol. 2015, 5, 4444

24. Shearer, G. C.; Chavan, S.; Ethiraj, J.; Vitillo, J. G.; Svelle, S.; Olsbye, U.; Lamberti, C.; Bordig, S.; Lillerud, K. P.; Chem.Mater 2014, 26, 4068.

25. Shearer, G. C.; Chavan, S.; Bordig, S.; Svelle, S.; Olsbye, U.; Lillerud, K. P.; Chem. Mater. 2016, 28, 3749.

26. Valenzano, L.; Civalleri, B.; Chavan, S.; Bordig, S.; Nilsen, M .H.; Jakobsen, S.; Lillerud, K. P.; Lamberti, C.; Chem. Mater 2011, 23, 1700 .

27. Miao, Z. C.; Qi, C.; Wensley, A. M.; Luan, Y.;RSC Adv. 2016, 6, 67226.

28. Sun, D. R.; Liu, W. J.; Mei, Q. M.; Zhang, Y. F.; Li, Z. C.; Commun. 2015, 51, 2056. 
29. Ghalei, B.; Sakurai, K.; Kinoshita, Y.; Wakimoto, K.; Isfahani, P.; Song, Q. L.; Doitomi, K.; Furukawa, H.; Hajime, H.; Kitagawa.S.; Sivaniah, E.; Nature Energy 2017, 2, 17086.

30. Karagiaridi, O.; Vermeulen, N. A.; Klet, R. C.; Wang, T. C.; Moghadam, P. Z.; Farha, O. K.; Inorg. Chem. 2015, 54, 1785.

31. Buragohain, A.; Biswas, S.; CrystEngComm. 2016, 18, 4374.

32. Sava, G. F.; Harvey, J.; Pearce, C.; Hall, M.; De Coste, Jared.; Kinnan, M.; Greathouse,J.; J.Mater.Chem.A 2018, 6, 3038.

33. Yang, J.M.; Ying, R. J; Han, C. X; Hu, Q. T; Xu, H. M.; Li, J. H.; Wang, Q.; Zhang, W.; Dalton Trans. 2018, 47, 3913.

34. Gao, X. C; Hai, X; Baigude, H.; Guan, W. H.; Liu,Z. L.; Scientific Reports 2016, 6, 37705.
35. Kaposi, M.; Cokoja, M.; Hutterer ,C. H.; Hauser, S. A.; Kaposi, T.; Klappenberger,F.;P̈tg, A.; Barth, J.; Herrmanna, W.; Kühn, F. E.; Dalton Trans. 2015, 44, 15976.

36. Trickett, C. A.; Gagnon, K. J.; Lee, S.; Felipe, G.; Bîrgi, H. B.; Yaghi, O. M.; Angew. Chem. Int. Ed. 2015, 54, 11162.

37. Ye, G.; Qi, H.; Li, X. L.; Leng, K. Y.; Sun, Y. Y.; Xu, W.; ChemPhysChem. 2017, 18, 1903.

38. Gadipelli, S.; Guo, Z. X.; Chem. Mater 2014, 26, 6333.

39. Gascón,V.; Miguel, E. C.; García, M. D.; Blanco, R. M.; Sanchez, S. M.; J Chem Technol Biotechnol. 2017, 92, 2583.

40. Kronast, A.; Eckstein, A.; Altenbuchner, P.T.; Hindelang, K.; Vagin, S.; Rieger, B.; Chem. Eur. J. 2016, 22, 12800 